\title{
Psychosocial challenges before and after organ transplantation
}

This article was published in the following Dove Press journal:

Transplant Research and Risk Management

4 August 2015

Number of times this article has been viewed

\author{
Karl-Heinz Schulz ${ }^{1,2}$ \\ Sylvia Kroencke ${ }^{1,2}$ \\ 'Department of Medical Psychology, \\ ${ }^{2}$ University Transplant Center, \\ University Medical Center Hamburg- \\ Eppendorf, Hamburg, Germany
}

\begin{abstract}
This review addresses psychosocial challenges before and after solid organ transplantation. Stressors, corresponding psychosocial changes of the recipient, and psychological interventions in the different phases of the transplant process are described. Furthermore, important aspects of the preoperative psychosocial evaluation are presented with a special focus on living donors and patients with alcoholic liver disease. For the postoperative period, adherence, quality of life, and return to work are highlighted. Finally, research and clinical implications are presented.
\end{abstract}

Keywords: adherence, alcoholic liver disease, evaluation, living donation, quality of life, return to work

\section{Introduction}

Organ transplantation has become an established treatment in end-stage organ failure. Even though it is now a routine procedure in many countries worldwide, patients are faced with various challenges. This review addresses psychosocial challenges and relevant psychological aspects in the different phases of the transplant process.

\section{Stressors before transplantation}

Chronic illnesses are not only accompanied by somatic changes and functional limitations but also by emotional, cognitive, and social changes requiring extensive adjustments and considerable coping skills (Table 1). These psychosocial changes should not be considered as secondary, since they are as much part of the illness as pathological blood parameters and somatic symptoms. From the first symptoms and diagnosis to the very acceptance of having to live with a chronic condition, the process of the growing realization of being chronically ill is accompanied by emotional crises and destabilization. Depressiveness and hopelessness, anxiety, aggression, hope, and confidence vary in an unpredictable pattern, representing the gradual process of adaptation. Various coping strategies are utilized. Their functionality is less determined by a specific strategy but rather by its flexible and adequate use. The internal adaptation process is accompanied by an increasing loss of autonomy, social roles (family and occupational), contacts, and activities. Furthermore, occupational and financial problems might cause existential worries. In end-stage organ failure, the patient has to face his/her limited life expectancy and the need for organ transplantation. Fear of death, inner conflicts, and the uncertainty of a timely transplantation are prevailing emotional stressors in this stage of the illness. In the case of kidney disease, dialysis
Correspondence: Karl-Heinz Schulz Department of Medical Psychology, University Medical Center HamburgEppendorf, Martinistrasse 52, W26, 20246 Hamburg, Germany

Tel +49407410 54I32

Fax +49 40741054965

Email khschulz@uke.de
Transplant Research and Risk Management 20I5:7 45-58 
Table I Generic course of a chronic disease before and after transplantation, patients' coping demands, and psychological interventions

\begin{tabular}{|c|c|c|}
\hline Disease course & $\begin{array}{l}\text { Patients' psychological reactions } \\
\text { and coping demands }\end{array}$ & Psychological interventions \\
\hline First symptoms & Adaptation to crisis & Crisis intervention \\
\hline Diagnosis & Attribution of meaning (subjective & Supportive therapy to facilitate illness acceptance and illness \\
\hline Living with a chronic illness & illness theory) & coping \\
\hline Persistent symptoms & Attempting to maintain personal & Facilitate adherence and knowledge/understanding of illness \\
\hline Frequent doctor visits and hospital stays & autonomy & (illness education) \\
\hline \multirow[t]{5}{*}{ Medical treatment } & Accepting changes in occupational and & Facilitate formation of new role perceptions and life goals \\
\hline & family roles & Family counseling \\
\hline & Developing new life goals & Mediate contact to patient support groups and targeted \\
\hline & Acquiring new coping strategies and & treatment measures (eg, detoxification therapy) \\
\hline & activating resources (eg, social support) & \\
\hline Preoperative stage & Decisional conflicts & Psychosocial evaluation \\
\hline Transplant evaluation & Uncertainty & Facilitate decision-making and adherence \\
\hline Waiting list & Helplessness, hopelessness & Facilitate coping with uncertainty and stress reduction \\
\hline Medical crises & Preoperative fear & Facilitate processing of fear, grief, depressiveness, and aggression \\
\hline \multirow[t]{2}{*}{ Hospitalization } & Fear of death & Family counseling \\
\hline & Acute stress reaction (shock) & Crisis intervention \\
\hline Perioperative stage & Postoperative delirium (acute & Facilitate processing of delirium/psychotic symptoms \\
\hline Complications & organic brain syndrome) & Facilitate organ integration and processing of "donor fantasies" \\
\hline \multirow[t]{4}{*}{ Acute rejection } & Organ integration & Facilitate processing of traumatic reactions, fear, and pain \\
\hline & Traumatic experiences & Support/encouragement in case of somatic crises \\
\hline & Fear of rejection & \\
\hline & Coping with complications & \\
\hline Postoperative stage & Fear of organ failure/loss & Facilitate fear processing and emotional stabilization \\
\hline Convalescence & Fear of infections and other & Facilitate adherence and readjustment \\
\hline New medical treatments & comorbidities (eg, cancer) & Crisis intervention \\
\hline Immunosuppressive medication & Coping with medical problems & Supportive therapy \\
\hline Side effects, associated comorbidities & Readjustment and adherence problems & Cognitive and behavioral interventions \\
\hline Rehospitalization & In case of graft failure: & Family counseling \\
\hline Chronic rejection & Hopelessness, depressiveness & Mediate contact to patient support groups \\
\hline \multirow[t]{3}{*}{ Retransplantation } & Feelings of guilt & \\
\hline & Increased fear of retransplantation & \\
\hline & and organ failure & \\
\hline
\end{tabular}

is available as an alternative treatment. It is, however, associated with diverse and severe limitations, especially regarding quality of life (QOL) and life expectancy.,2

\section{Stressors after transplantation}

In the perioperative period, the focus is on the patient's physical recovery, with possible rejection episodes and other medical complications causing anxiety and emotional strain. Within the first days after transplantation, a postoperative delirium (acute organic brain syndrome) might occur. The accompanying symptoms of mental confusion, language disturbances, and occasional hallucinations and delusions are often a frightening experience to patients and their families. Acute brain dysfunction is common in intensive care patients and patients after surgery. ${ }^{3-6}$ In transplant patients, the immunosuppressive medication, especially corticosteroids, is known to contribute to this syndrome. ${ }^{7}$ Although the symptoms are reversible in the majority of transplant patients, their occurrence is associated with longer hospital stay and higher mortality. ${ }^{8-10}$ Some patients experience problems accepting the new organ and suffer feelings of guilt toward the donor which, in turn, can increase psychological stress and nonadherence. ${ }^{11}$ In addition, the transplant and intensive care unit experience may cause symptoms of post-traumatic stress disorder or reactivate preexisting traumata. ${ }^{?}$

In the long-term postoperative period, medication side effects and associated comorbidities become central stressors impeding patients' QOL. Frequent comorbidities are infections, diabetes mellitus, hypertension, lipometabolic disorders, adipositas, cardiovascular diseases, oncologi- 
cal diseases, osteoporosis, and chronic kidney failure. ${ }^{12,13}$ Furthermore, psychiatric symptoms (eg, depression, anxiety, agitation, psychosis) and neurological symptoms (eg, sleep disturbances, cognitive impairment, delirium) can occur as neurotoxic side effects in patients receiving immunosuppressive drugs. ${ }^{7,14}$ In most cases, episodes of acute rejection can be treated effectively, especially in the early postoperative period, whereas chronic rejection still constitutes a serious problem. Organ failure can be caused by the recurrence of the underlying disease (eg, hepatitis $\mathrm{C}$ following liver transplantation) or by chronic rejection and other immune-mediated as well as non-immunological factors (eg, hypertension, smoking, nonadherence) leading to irreversible organ damage (chronic allograft nephropathy in kidney transplantation, cardiac allograft vasculopathy in heart transplantation, bronchiolitis obliterans syndrome in lung transplantation, chronic liver allograft failure in liver transplantation). Graft failure along with infections is the leading cause of long-term mortality in heart and lung transplantation, ${ }^{15,16}$ while patients after liver and kidney transplantation more often die of cardiovascular diseases. ${ }^{12,17}$ Graft failure in kidney transplant recipients is primarily caused by chronic allograft nephropathy, ${ }^{18}$ whereas in liver transplant recipients, disease recurrence and biliary problems are the most common causes of graft dysfunction. ${ }^{12}$ Furthermore, the need for kidney transplantation can also arise in heart, liver, and lung transplant patients, mainly due to the nephrotoxic effects of the immunosuppressive medication. ${ }^{19}$ In all transplant patients, cancer presents an increasing mortality risk in the long-term postoperative period. ${ }^{12,15-17}$

Faced with these multiple health risks, patients often continue to experience anxiety and worries regarding possible retransplantation, serious comorbidities, and death. It could be demonstrated that, irrespective of their health status, lung transplant patients' transplant-associated worries are correlated with increased chronic stress. ${ }^{20}$ Should retransplantation actually become necessary, emotional strain increases further. But even patients in good physical health are confronted with severe challenges, for example, regaining their previously lost or restricted social roles as family members and partners (including sexual activity) and returning to work or taking up other meaningful activities. ${ }^{21,22}$ Financial problems and legal disputes with health or pension insurance agencies constitute other possible sources of psychological strain. In a study assessing patients 5 years and 10 years after heart transplantation, the most bothersome stressors concerned work, school, and financial issues. ${ }^{23}$ Furthermore, patients might feel stressed by the need for a healthy lifestyle (eg, regular physical activity, weight control, alcohol and tobacco abstinence) and the strict adherence to the medical regimen (eg, punctual intake of medication, frequent follow-up appointments, dietary restrictions, and infection prophylaxis). This, in turn, might compromise their adherence after transplantation.

\section{Psychosocial adaptation and psychological disorders}

After transplantation, the psychosocial burden is usually less severe than during the preoperative period. Nevertheless, patients must still be regarded as chronically ill and have to demonstrate considerable coping skills. In the best case, transplant patients learn to adapt to their new situation, often by reevaluating life goals and by focusing on more positive consequences, for example, personal growth. ${ }^{24}$ On the other hand, unsuccessful readjustment is associated with lower QOL and psychiatric morbidity. ${ }^{14,25,26}$ The most common psychological disorders among patients before and after transplantation are affective and anxiety disorders. ${ }^{7,14}$

Comprehensive literature reviews demonstrate a prevalence of depression in $20 \%-25 \%$ of cases before and after kidney transplantation. ${ }^{27-29}$ Less information is available concerning patients receiving other organs. Prior to and following lung transplantation, depression seems to be prevalent in approximately $30 \%$ of patients. ${ }^{30,31}$ Furthermore, lung transplant patients are more likely to suffer from anxiety disorders, especially panic disorder. ${ }^{7,31}$ In heart and liver transplantation, most studies find symptoms of depression and anxiety in at least $30 \%$ and up to $60 \%$ of patients..$^{7,32-41}$ A recent crosssectional study of patients after liver transplantation relates the different rates of depressive and anxiety symptoms to the time elapsed since transplantation, with symptoms being more prevalent in the first 2 years and beyond 15 years after transplantation. Post-traumatic stress symptoms were more prevalent within the first 5 years after transplantation. ${ }^{42}$

The extent of the perceived psychosocial burden is moderated by personal and social resources (resilience factors), that is, favorable coping skills, self-efficacy, sense of coherence, optimism, and social support. ${ }^{23,24,31,43-47}$ Furthermore, associations of psychosocial variables with medical outcome and even mortality in transplant patients could be demonstrated. ${ }^{14,25,29,32,48-52}$ DiMartini et al ${ }^{52}$ identified three different trajectories of depressive symptoms within the first postoperative year in a cohort of 167 liver transplant patients with alcoholic liver disease (ALD): group 1 with consistently low depression levels, group 2 with initially low depression 
levels that increased over time, and group 3 with consistently high depression levels. Groups 2 and 3 showed significantly higher mortality within the subsequent years (controlling for age and medical variables commonly associated with mortality). The strongest predictors of mortality were depression scores and number and severity of comorbidities. Rogal et $\mathrm{al}^{35}$ found untreated depression as the factor most strongly linked to long-term mortality after liver transplantation.

\section{Psychological care}

Psychological consultation can be helpful in all disease stages enabling patients to better cope with their extraordinarily stressful situation (Table 1). A need for psychological care was found in up to $50 \%$ of transplant patients. ${ }^{53,54}$ Of particular importance are educational and supportive therapy elements but also cognitive-behavioral interventions including relaxation techniques. ${ }^{55-57}$ Less common methods like hypnotherapy ${ }^{58}$ and "Quality of Life Therapy"59 have also been utilized. Gross et $\mathrm{al}^{60}$ were able to demonstrate a positive effect of "Mindfulness-Based Stress Reduction" on transplant patients' depression, anxiety, and sleep quality. Dew and DiMartini $^{40}$ advise a multicomponent interventional approach focused on risk factor reduction and the enhancement of personal coping resources. However, interventional studies are still rare, and further research is necessary regarding the effectiveness of interventions in order to develop evidencebased therapy strategies.

Moreover, family members and caregivers of transplant patients show increased psychological strain before and after transplantation. ${ }^{61}$ Family counseling, and if necessary, psychotherapeutic support, can help reduce psychological strain, thus also maintaining the valuable social support provided by caregiving family members of the transplant patient. In this context, the issue of possible conflicts due to changing family roles may also be addressed.

\section{Psychosocial evaluation}

In the preoperative period, the psychosocial evaluation of transplant patients is an important psychological task, particularly in view of the prevailing organ shortage. Similar to the medical evaluation, the psychosocial evaluation should be evidence-based and avoid any moral judgment. The procedure should aim at identifying factors likely to have a negative impact on the postoperative prognosis. The goal should not be the exclusion of patients from transplantation but rather the recommendation of supportive or therapeutic measures which, upon successful completion, enable access to the waiting list (at a later date). Final exclusion is to be considered only if cooperation with the patient cannot be achieved in the long term, thus making graft loss highly probable.

A psychosocial evaluation should be part of every transplant program. In its course, cognitive, behavioral, emotional, and social factors that might impair coping or adherence should be explored, and the patient and his/her family should be prepared as best as possible for transplantation. Table 2 shows evaluation criteria as well as critical results. In most cases, problematic evaluation results need not be considered as contraindications for transplantation, since modification is possible, for example, education in case of inadequate knowledge, counseling or psychotherapy in case

Table 2 Psychosocial evaluation criteria and critical results

\begin{tabular}{|c|c|}
\hline Evaluation criteria & Critical results \\
\hline Disease acceptance & $\begin{array}{l}\text { Denial/lack of acceptance of illness or necessity for } \\
\text { transplantation }\end{array}$ \\
\hline Knowledge regarding disease and transplantation & Lack of knowledge \\
\hline Transplant motivation & Lack of motivation to receive a transplant \\
\hline Expectations regarding transplant outcome & Unrealistic expectations \\
\hline Past and present coping behavior & Inadequate coping behavior \\
\hline Past and present adherence & Inadequate adherence \\
\hline Health behavior & Inadequate health behavior \\
\hline Substance use (alcohol, tobacco, illicit drugs) & Substance abuse \\
\hline Past and present addictive behavior & Substance dependence \\
\hline Past and present psychiatric disorders & Active psychiatric disorder \\
\hline Symptoms of anxiety, depression & Severe symptoms of anxiety/depression \\
\hline Cognitive status, capacity to give consent and adhere to the medical regimen & Cognitive deficits, inability to give consent/adhere \\
\hline Social anamnesis (living arrangements, relationships, social support) & Unstable/problematic relationships, lack of social support \\
\hline Occupational situation and post-transplant expectations/goals, economic situation & $\begin{array}{l}\text { Occupational and/or financial problems, unrealistic goals } \\
\text { (under- or overstated) }\end{array}$ \\
\hline Other psychosocial stressors & High psychosocial burden \\
\hline
\end{tabular}


of psychiatric disorders, and inadequate coping, activation of family support, or outpatient care for patients needing help taking their medication. A history of psychiatric disorders is not to be considered as absolute contraindication for transplantation. ${ }^{14}$

As opposed to post-transplant psychological disorders, pretransplant psychopathology does not seem to be as strongly associated with the medical outcome of transplantation. ${ }^{50,62}$ Even in case of psychotic or major depressive disorders, a favorable long-term outcome can be achieved with specialized treatment, good social support, and regular follow-up visits. ${ }^{50}$ Regarding cognitive disorders, it is important to attempt a differentiation between potentially reversible deficits due to organ dysfunction (eg, hepatic encephalopathy, uremic encephalopathy) and more persistent deficits that might be due to preexisting dementia or a static cognitive impairment. While the restoration of normal organ function may most likely correct the reversible cognitive impairments, there is growing evidence that some patients continue experiencing cognitive deficits after transplantation. ${ }^{63-66}$ Special attention is necessary regarding substance-induced disorders leading directly (eg, alcoholic liver or heart disease, acute liver failure due to acetaminophen poisoning) or indirectly (eg, hepatitis $\mathrm{B} / \mathrm{C}$ cirrhosis due to intravenous drug abuse) to transplantation. ${ }^{67}$

Jowsey et $\mathrm{a}^{68}$ listed the following risk factors for poor transplant outcome:

- Weak or absent support systems

- History of nonadherence

- Active psychiatric pathology

- Significant cognitive impairment or moderate/severe mental retardation or dementia

- Personality disorders with impulsivity.

Whether or not these criteria should be taken as contraindications for transplantation, however, should be decided on a case-by-case basis by an interdisciplinary team considering all available medical and psychosocial information.

\section{Psychosocial evaluation in living organ donation}

In kidney and liver transplantation, living donation has become a routine procedure in many centers worldwide with the majority of donors showing good QOL outcomes. ${ }^{69-72}$ In some countries, the majority of transplanted organs are procured from living donors. ${ }^{73}$ Psychosocial evaluation of living donors has to consider national legal prerequisites. Whereas, in some countries, a close genetic or emotional relationship between donor and recipient is required, others permit unrelated or even anonymous (unspecified) donation. ${ }^{74}$
A systematic literature review assessing guidelines, consensus statements, and clinical protocols describing the psychosocial evaluation of living donors concludes that the current evidence base of psychosocial evaluation criteria is weak and there is a wide variation of methods used to evaluate donors. ${ }^{75}$ Most authors recommend the use of a structured or semistructured interview providing a framework for comprehensive assessments. Several propose additional psychometric testing. Psychosocial domains frequently addressed in donor evaluation are the following:

- Motivation to donate, decision-making process, ambivalence, expectations

- Voluntariness of the decision

- Cognitive status, competence to give informed consent

- Knowledge regarding own and recipient's risks

- Sociodemographic characteristics, family-related issues, social support

- Donor-recipient relationship

- Current and past psychiatric disorders, psychological stability

- Current stressors, critical life events, coping

- Adherence with the medical regimen, health behavior including substance use

- Financial issues, for example, economic risks of donation, possible financial inducements (prohibition of organ trafficking)

- Employment-related issues, for example, occupational risks of donation.

The recipient interview in case of living donation should also include an exploration of the relationship with the donor as well as the recipient's attitude toward living donation and possible associated expectations.

\section{Psychosocial evaluation of patients with ALD}

Even though alcohol-related liver disease has become one of the most common indications for liver transplantation in Europe and the USA, it remains the most controversially discussed indication. ${ }^{76-78}$ Compared to patients with other disease etiologies, survival of patients with alcoholic liver cirrhosis is similar ${ }^{78,79}$ or even better. ${ }^{80}$

Liver damage from alcohol varies from asymptomatic, and in most cases, reversible steatosis to cirrhosis with subsequent risk of hepatocellular carcinoma. Factors influencing disease development include the dose, duration, and type of alcohol consumption, drinking patterns, sex, ethnicity, and associated risk factors including obesity, iron overload, concomitant infection with viral hepatitis, and genetic factors. ${ }^{81,82}$ 
The medical diagnosis of ALD is to be differentiated from the psychiatric diagnoses of "alcohol abuse" or "alcohol dependence". ALD diagnosis is based on histological and laboratory markers along with the patient's admission of having consumed excessive amounts of alcohol. Patients, however, will often downplay or even deny alcohol consumption, and the other diagnostic criteria lack specificity, especially if considered individually. Even without pathophysiological evidence of organ damage, severe addictive behavior can be present. At the same time, alcohol-induced organ damage is not necessarily accompanied by addictive behavior, and only approximately $30 \%$ of patients with continued alcohol consumption ( $>40 \mathrm{~g} /$ day) progress from steatosis to liver cirrhosis. ${ }^{83}$ The percentage declines to $15 \%$ if abstinence can be achieved. ${ }^{81}$

The importance of differentiating between ALD and alcohol abuse/dependence is demonstrated in a retrospective study by Rowley et al. ${ }^{84}$ With a median follow-up time of 6 years, the authors assessed $n=358$ liver transplant recipients, $22 \%$ of whom had a transplant indication of ALD. In ten out of these 77 patients, clinical psychologists could not ascertain a psychiatric diagnosis of alcohol dependence or alcohol abuse (according to Diagnostic and Statistical Manual of Mental Disorders IV - Text Revision criteria), whereas in 54 patients without ALD diagnosis, alcohol abuse or dependence could be diagnosed. This newly defined group of $n=121$ patients included $34 \%$ of the study sample, overlapping approximately by half with the ALD group. While ALD diagnosis did not predict survival, patients classified according to psychiatric diagnosis had significantly poorer survival rates than patients without psychiatric diagnosis ( 7.3 years, 95\% confidence interval: $6.3-8.3$ versus 9.4 years, 95\% confidence interval: 8.7-10.1). No significant difference was found between patients with alcohol dependence and alcohol abuse. Thus, psychiatric diagnostic criteria appear to have greater utility in predicting survival than the pathophysiologically defined ALD diagnosis. This might be due to harmful behavioral consequences of substance addiction (ie, impaired sleep, unhealthy eating habits, low social support, nonadherence to the immunosuppressive regimen) having a negative impact on long-term survival as “... transplant surgery is not considered a cure for maladaptive behavior" (p 202).$^{84}$ In fact, drug addiction was found to be another independent predictor of mortality in this study. In addition, more frequent comorbidities (cardiovascular diseases, de novo neoplasms) in patients with substance misuse as well as alcohol relapse and tobacco consumption are associated with reduced postoperative survival. ${ }^{79,80,85-87}$ A literature review concludes that excessive drinking after transplantation is associated with worse patient outcomes regardless of primary transplant indication. ${ }^{88}$ In a study comparing survival of patients with and without alcohol relapse, 5-year and 10 -year survival was $70 \%$ and $20 \%$, respectively, in patients with excessive alcohol consumption versus $90 \%$ and $82 \%$, respectively, in abstinent patients. ${ }^{89}$ Thus, especially, long-term survival is reduced.

Alcohol relapse rates after transplantation vary widely between $10 \%$ and $50 \%,{ }^{79}$ depending on preoperative selection, postoperative care, methods used to assess alcohol relapse, and the definition of what constitutes a relapse (eg, any consumption versus harmful drinking). Approximately 20\% return to harmful drinking after transplantation. ${ }^{78}$ A major challenge of the preoperative evaluation is to assess the probability of relapse after transplantation. The predictive value of the duration of preoperative abstinence is still under discussion, but evidence of newer studies assessing large samples suggests that a longer period of abstinence is associated with lower relapse rates. ${ }^{89-92}$ In most centers, a minimum of 6 months is determined as an adequate length of sobriety ("6-month rule"). However, exceptions can be justified in case of patients with predicted survival of $<6$ months, especially if other prognostic factors are in favor of the patients' abstinence. There is even evidence that selected patients with acute severe alcohol hepatitis receiving a transplant without observing a period of abstinence derive a benefit from transplantation similar to that achieved for other indications. ${ }^{76,88,93}$ Thus, some authors argue against the 6-month rule being used as a major selection criterion. ${ }^{88,94}$ Apart from a shorter duration of preoperative sobriety, literature reviews ${ }^{95-98}$ found the following predictors relevant to the prognosis of post-transplant alcohol relapse: family history of alcohol abuse/dependence, other substance misuse, abuse versus dependence, psychiatric comorbidity, younger age, lack of social support, preoperative drinking pattern (eg, high frequency, large amounts of alcohol), repeated treatment failures, and nonadherence with medical care. The preoperative evaluation is based on these criteria, along with other emerging predictors, such as nonacceptance of having an alcohol problem, low motivation for change, and lack of self-esteem. ${ }^{82,99}$ Thus, psychosocial evaluation in case of ALD should include the following:

- Individual and family history of alcohol consumption

- Drinking patterns (type and amount of alcohol, frequency)

- Withdrawal treatments

- Diagnosis of abuse versus dependence

- Duration of abstinence 
- Nonalcohol-related substitute activities

- Negative social consequences in case of relapse

- Social support/stability (vocational situation, family, friends, relationship with husband/wife/partner, living conditions)

- Other substance use

- History of adherence (regarding substance use and medical treatment)

- Acceptance of alcoholic disease etiology

- Motivation for change

- Self-esteem, hope, and confidence.

Failure to meet these criteria, however, should not lead to ultimate exclusion but rather to a diagnosis of deficits to develop treatment recommendations. ${ }^{100}$ With a careful preoperative psychosocial evaluation and life-long medical and psychological follow-up, including regular monitoring of alcohol consumption and early treatment of relapse, good long-term results can be achieved ${ }^{76}$ with relapse rates lower than or similar to intense inpatient relapse prevention treatment. ${ }^{101}$

\section{Adherence}

For the long-term success of transplantation, adherence is an essential prerequisite as nonadherence can lead to graft rejection, graft loss, and even death. Prior to transplantation, continued nonadherence is considered a contraindication for transplantation. This constitutes an ethical dilemma of patient autonomy and the right to receive treatment versus the necessity to limit access to transplantation due to the scarcity of donor organs. Thus, the evaluation and promotion of adherence is a key objective in transplant psychology.

Nonadherence means "not taking medications, missing medications, taking too much, not taking enough, wrong timing, wrong dose and/or wrong pill, but may also refer to missing appointments, not booking appointments, not doing blood work, not returning calls and/or refusal to follow the treatment regimen" ( $p$ 27). ${ }^{102}$ Furthermore, adherence in transplant patients also refers to observing hygiene rules and specific dietary regimens as well as adequate health behavior and substance use. Compared to the common term "compliance", adherence is of less instructive character and focuses more on doctor-patient cooperation and the jointly negotiated treatment plan. Accordingly, the reasons for nonadherence not only reside in the patient but also within the physician's behavior and the doctor-patient relationship. In addition, treatment characteristics like the number, intake frequency, and (perceived) side effects of drugs influence adherence behavior.
It can be estimated that approximately $50 \%$ of late acute rejections and $15 \%$ of graft losses are associated with nonadherence. ${ }^{103}$ Along with medication nonadherence, tobacco consumption seems to be a contributing factor which further increases the postoperative risk of developing comorbidities. ${ }^{104}$ According to a meta-analysis, approximately 23 out of 100 adult transplant patients per year fail to take their immunosuppressants correctly. ${ }^{105}$ The authors found similarly high nonadherence rates regarding diet, exercise, and other health care requirements. However, rates vary between patient groups and depending on age. Medication nonadherence is highest in kidney recipients ${ }^{105}$ and in adolescent transplant patients with estimated rates of $>50 \%$. ${ }^{106}$ With respect to substance use, it was found that approximately ten out of 100 adult patients per year resume smoking, six out of 100 take up drinking alcohol again, and four out of 100 experience illicit drug relapse. ${ }^{107}$ The variety of methods used to quantify adherence also contribute to the wide range of reported nonadherence rates, with De Bleser et al ${ }^{108}$ reporting immunosuppressive medication nonadherence rates of $24 \%-70 \%$ depending on the measurement method.

Despite the clinical relevance of adherence with respect to the long-term outcome of transplantation, there currently exists no single method considered as the gold standard to assess medication nonadherence. ${ }^{109}$ Electronic monitoring with microdevices recording each opening of the pill bottle gives the most accurate insight into patient behavior and is recommended for research studies. ${ }^{110}$ It is, however, too cost-intensive and usually not available in clinical practice. Methods like pill counts and prescription refill rates are difficult to monitor in clinical practice and reveal nothing about the timing of ingestion. ${ }^{111}$ Patient self-reporting by interview, diary, or questionnaire, and proxy reports by clinicians or family members are inexpensive and feasible in most clinical settings, but these methods are prone to recall and social desirability response bias. Proxy reports depend on the familiarity with the patient. ${ }^{112}$ Butler et al $^{113}$ found that clinicians' rating yielded even more inaccurate results compared to electronic monitoring than self-report at a confidential interview. However, high specificity can be reached with collateral reports of at least three clinicians. ${ }^{12}$ Self-report questionnaires have been developed which can be useful in detecting nonadherence; however, further validation of these measures is needed in transplant populations. ${ }^{109}$ No conclusive biological markers of medication nonadherence have yet been identified. Blood-level monitoring of immunosuppressive medication did not prove useful when only single measurements were considered. More reliable results can be 
achieved by assessing the variability in immunosuppressant trough levels over a longer period of time. ${ }^{114,115}$ In clinical practice, combining different assessment methods, such as self-reporting, clinical judgment, and variability in immunosuppressant blood levels, is advised. ${ }^{109,111,112}$

Studies have identified a variety of variables predicting nonadherence, but reviews are inconclusive. The best predictor of postoperative nonadherence seems to be preoperative adherence behavior. ${ }^{105,116}$ Furthermore, an association was found between medication nonadherence and a high perceived symptom burden due to the immunosuppressive medication ${ }^{117}$ as well as negative attitudes toward the immunosuppressive medication. ${ }^{118}$ Other frequently identified predictors of nonadherence are age (adolescence and very old age), psychiatric disorders, substance abuse, and a lack of social support. ${ }^{118-120}$ Dew et al ${ }^{121}$ found that the probability of nonadherence increases with the number of risk factors or predictors present: with $0-1$ risk factors, the probability was $30 \%$, increasing to $50 \%$ with $2-3$ risk factors and to $80 \%$ with $\geq 4$ risk factors.

A small number of intervention studies show that posttransplant adherence can be improved, but the available data are inconsistent with only five out of 12 studies reviewed by De Bleser et $\mathrm{al}^{103}$ showing significant improvement in at least one medication adherence outcome. Most interventions include a combination of patient-focused cognitive/ educational, behavioral, emotion-centered, and social support-activating dimensions. The most promising approach is seen in a paradigm shift from cure to prevention, with a continuous routine assessment of nonadherence focusing on its individual reasons, followed by a combination of tailored interventions addressing the underlying causes of the problematic behavior in an interdisciplinary setting. ${ }^{103,106}$ Future studies should also explore the communication skills of physicians, nurses, and other transplant professionals with respect to promoting adherence and whether improving their adherence management skills can improve transplant patients' outcome. ${ }^{106}$

\section{Quality of life}

The term "health-related quality of life" describes the extent to which the habitual or expected physical, emotional, and social well-being is affected by a medical condition or its treatment. In former years, transplantation medicine was primarily oriented toward patient survival, that is, the quantity of life years gained. With the improvement of long-term outcomes, the focus has shifted to the quality of the years gained and the perception from a patient point of view.
Today, QOL is acknowledged as a main outcome parameter in transplantation medicine, the aim being to restore patients' physical, psychological, and social functioning. Some studies even identified QOL as a significant predictor of mortality and graft failure after transplantation. ${ }^{51,122}$

A considerable number of prospective and retrospective studies with large samples have been published along with $>20$ literature reviews summarizing results across either different types of organs or organ-specific procedures. Systematic reviews and meta-analyses ${ }^{123-132}$ mostly assessed QOL in liver and kidney recipients (including combined pancreas transplantation), but overviews are also available for heart and lung transplantation ${ }^{49,133-136}$ and even for small intestine transplantation. ${ }^{137}$ Anthony et al ${ }^{138}$ reviewed QOL in pediatric patients across all organ types, while Kniepeiss et $\mathrm{al}^{139}$ focused on QOL in elderly patients. Other reviews considering QOL across different organ types are available from Burra and De Bona, ${ }^{140}$ Ortega et al, ${ }^{141}$ Feurer et al, ${ }^{142}$ Schulz et al, ${ }^{143}$ Dew et al, ${ }^{123}$ and Molzahn. ${ }^{144}$ It should be noted that especially in early studies, the definition of QOL and its measurement differed considerably. Until today, there is no gold standard for measuring QOL. Instead, a variety of generic and disease-specific instruments have been applied. ${ }^{145,146}$ The most commonly used QOL instrument in transplantation medicine is the 36-Item Short-Form Health Survey by Ware and Sherbourne. ${ }^{147}$ However, as a generic instrument, its possible shortcomings to capture aspects of health relevant and specific to transplantation should be kept in mind.

Current evidence suggests that postoperative QOL is clearly superior to preoperative QOL. The gain is larger in scales affected by physical health, whereas improvements are less distinctive in areas affected by psychosocial functioning. ${ }^{140}$ In single dimensions, like sexual function and occupational rehabilitation, deficits appear to persist after transplantation. ${ }^{21,49,148,149}$ QOL was found to be significantly better compared to specific reference groups of chronically ill patients not receiving a transplant. In contrast, results comparing transplant patients to the general population or healthy controls are inconsistent, with studies finding worse, similar, or even better QOL scores. The latter, however, might be attributed to a change in patients' appraisal of QOL and to selection effects. In conclusion, QOL in transplant patients is probably lower than within the general population. ${ }^{143}$ Nevertheless, even in the long term $(\geq 10$ years after transplantation), a good QOL can be achieved. ${ }^{38,150-153}$ Yet, organ-specific or disease-specific factors may negatively influence postoperative QOL..$^{49,123,154,155}$ Furthermore, studies 
often are limited by methodological problems as there is no correction for confounding variables, such as age, sex, and other potential biases (eg, socioeconomic and educational status, hemoglobin concentration, diabetes mellitus, renal function). ${ }^{141}$

Other factors possibly influencing postoperative QOL are specific complications, the immunosuppressive treatment and its adverse effects, comorbidities, and the disease course prior to and after transplantation, especially disease recurrence and graft failure. ${ }^{143}$ Strong associations with physical and mental QOL could also be demonstrated for distinct coping strategies, anxiety, depression, and employment. These psychosocial factors were far more relevant to QOL than purely somatic variables, such as the number of postoperative complications or length of hospital stay. ${ }^{156}$ As determinants predicting a higher QOL, the following variables were found: lower burden of immunosuppressive treatment, better social integration, higher income/education, employment after transplantation, younger age for physical QOL, and older age for mental QOL. ${ }^{157,158}$ The type of transplanted organ appears to be less relevant in terms of QOL. In some studies, organ-specific differences were found, but not all of these are consistent. Prior to transplantation, Pinson et al ${ }^{155}$ and Ortega et a ${ }^{141}$ demonstrated the best QOL in kidney patients, followed by liver, heart, and lung patients. Ten years after transplantation, Karam et $\mathrm{a}^{153}$ reported the best QOL in liver transplant recipients, a medium QOL in heart recipients, and the lowest in kidney recipients. Kugler et al, ${ }^{159}$ on the other hand, found the smallest QOL benefit in liver transplant recipients within 2 years after transplantation. Ortega et al ${ }^{141}$ reported the best QOL in kidney recipients 3 months posttransplant, followed by heart recipients, and then liver recipients, with lung transplant patients showing the worst QOL. At 1 year, however, lung recipients had the best QOL. It can be summarized that improvements were found for all types of transplants, but the trajectories were not the same. Because of their superior preoperative QOL, kidney recipients seem to experience the smallest benefit, ${ }^{141,153,155}$ while lung recipients have the largest benefit in terms of QOL. ${ }^{141,159-161}$

In conclusion, postoperative QOL is associated with demographic, clinical, and psychosocial variables. Depending on the age group, different predictors may be relevant. ${ }^{162}$ Studies comparing QOL in different samples should therefore always correct the results for confounding variables, especially age and sex. Moreover, predictors may change within the postoperative course. ${ }^{154}$ To explore these complex interrelations, more research, especially prospective studies, is needed with the aim of developing a model to better understand risk factors for inferior QOL outcomes and determine interventions that positively influence these factors. Furthermore, previous research has been mostly deficit-oriented, while future studies should, instead, focus on resources and conditions for a better QOL.

\section{Return to work}

Enabling patients to take up productive employment constitutes a main goal of transplantation ${ }^{55}$ and is regarded as an indicator of societal participation. ${ }^{163}$ Prevalence rates of patients actually returning to work or finding new employment show a wide range between $18 \%$ and $86 \% .^{22,163-165}$ The heterogeneous results can be attributed to differing sociodemographic and clinical characteristics, length of follow-up time, definition of "work" (whether part-time employment or housework is included), assessment methods, and inclusion criteria (eg, whether retirees are categorized as nonworking) as well as national legal and social framework of health care, social security, and the labor market. Furthermore, although patients more frequently report feeling able to work, fewer actually do work. ${ }^{166,167}$ On the other hand, patients may have to take up employment, even though they do not feel able to work. In a Belgian study, the employment rate was highest in kidney transplant recipients with 59\%. Employment rates in heart and liver transplant recipients were $44 \%$ and $38 \%$, respectively. The lowest rate of $28 \%$ was found in lung transplant patients. ${ }^{21}$

As a strong predictor of return to work, a shorter duration of previous unemployment/disability was identified. ${ }^{21,22,163,165,167}$ Associations with return to work were also found for sociodemographic variables like younger age, male sex, and higher education ${ }^{21,22,165}$ as well as for the postoperative health status (complications and comorbidities, eg, diabetes) of transplant patients. ${ }^{167-169}$ Barriers keeping patients from returning to work include not only the fear of losing insurance coverage and financial support but also a lack of information and/or tools on how to realize their goals, for example, inadequate vocational rehabilitation, skills training, job placement assistance, ${ }^{170}$ and a lack of support from employers. ${ }^{165}$ Furthermore, a number of patients reported low subjective motivation or ability to work ${ }^{167}$ and a lack of confidence $^{171}$ as reasons for not taking up employment after transplantation. Patients' subjective health perception relating to their perceived ability or inability to work appears to be a significant predictor of return to work. ${ }^{166,167,170}$ In a study by Slakey and Rosner, ${ }^{166}$ kidney transplant patients considered their disability status more related to having received a transplant than to any specific physical limitation. This might be 
due to the often prolonged period of preoperative disability with frequent severe physical impairment. The modification of patients' perception of disability after transplantation is, therefore, seen as an important goal in enhancing employment rates. ${ }^{170}$ However, it is difficult to differentiate between perceived disability and actual impairments. Van der Mei et $\mathrm{al}^{172}$ found high levels of fatigue and physical impairment even in employed kidney transplant recipients, while, with a substantial variation among patients, in liver transplantation, poor health or health problems are cited as the most common reason for nonemployment. ${ }^{165}$

A number of studies have shown that more patients could take up employment than actually do return to work, and Huda et al ${ }^{165}$ conclude that "social rehabilitation ... lags behind the medical results of transplantation" ( $p$ 238). Important requirements for return to work are improvement of health status, patients' own motivation, and social support at the workplace. It has been demonstrated that patients employed after transplantation showed better QOL ${ }^{22,165,173}$ and less depression ${ }^{174}$ than patients not working. Due to the mainly cross-sectional study design, it remains unclear whether better well-being is cause or consequence of employment. Evidence exists, however, that, with targeted interventions, return to work can be facilitated. ${ }^{170}$

\section{Perspective}

Although knowledge concerning psychosocial aspects of transplantation has considerably increased over the last decades, the evidence base in most areas of research still does not permit definitive conclusions. This article gives an overview of the current evidence regarding some of the most relevant topics. More in-depth information regarding these and other topics is available. $7,14,48,55,67,68,175,176$ Furthermore, the scope of this review is limited to adult transplant recipients as priorities in pediatric transplantation are different in a number of areas. ${ }^{177-180}$ Future research should focus on factors influencing long-term outcomes and methods to assess and promote adherence as a main and modifiable determinant of transplant outcome. In many transplant centers, a lot of effort and resources are spent on preoperative evaluation and perioperative management, while during long-term follow-up, the attention patients receive is comparably low. Medical follow-up should be more easily available and complemented with routine psychosocial monitoring and interventions to assist patients in coping with the numerous demands they are faced with. Continuous attention seems warranted in order to optimize long-term success of transplantation.

\section{Disclosure}

The authors report no conflicts of interest in this work.

\section{References}

1. Avramovic M, Stefanovic V. Health-related quality of life in different stages of renal failure. Artif Organs. 2012;36(7):581-589.

2. Schulz KH, Thaiss F. Langzeitüberleben bei chronischer Niereninsuffizienz. [Long-term outcome with end-stage renal disease - survival is not enough: does dialysis or kidney transplantation matter?]. Bundesgesundheitsblatt Gesundheitsforschung Gesundheitsschutz. 2012;55(4):543-551. German.

3. Barr J, Fraser GL, Puntillo K, et al; American College of Critical Care Medicine. Clinical practice guidelines for the management of pain, agitation, and delirium in adult patients in the intensive care unit. Crit Care Med. 2013;41(1):263-306.

4. Rudolph JL, Marcantonio ER. Postoperative delirium: acute change with long-term implications. Anesth Analg. 2011;112(5):1202-1211.

5. Sanders RD, Pandharipande PP, Davidson AJ, Ma D, Maze M. Anticipating and managing postoperative delirium and cognitive decline in adults. BMJ. 2011;343:d4331. doi: 10.1136/bmj.d4331.

6. Zhang H, Lu Y, Liu M, et al. Strategies for prevention of postoperative delirium: a systematic review and meta-analysis of randomized trials. Crit Care. 2013;17(2):R47.

7. DiMartini A, Crone C, Fireman M, Dew MA. Psychiatric aspects of organ transplantation in critical care. Crit Care Clin. 2008;24(4):949-981.

8. Lescot T, Karvellas CJ, Chaudhury P, et al. Postoperative delirium in the intensive care unit predicts worse outcomes in liver transplant recipients. Can J Gastroenterol. 2013;27(4):207-212.

9. Smith PJ, Rivelli SK, Waters AM, et al. Delirium affects length of hospital stay after lung transplantation. J Crit Care. 2015;30(1):126-129.

10. Alejaldre A, Delgado-Mederos R, Santos MÁ, Martí-Fàbregas J. Cerebrovascular complications after heart transplantation. Curr Cardiol Rev. 2010;6(3):214-217.

11. Goetzmann L, Irani S, Moser KS, et al. Psychological processing of transplantation in lung recipients: a quantitative study of organ integration and the relationship to the donor. Br J Health Psychol. 2009; 14(pt 4):667-680.

12. Åberg F, Isoniemi H, Höckerstedt K. Long-term results of liver transplantation. Scand J Surg. 2011;100(1):14-21.

13. Lim KB, Schiano TD. Long-term outcome after liver transplantation. Mt Sinai J Med. 2012;79(2):169-189.

14. Heinrich TW, Marcangelo M. Psychiatric issues in solid organ transplantation. Harv Rev Psychiatry. 2009;17(6):398-406.

15. Stehlik J, Edwards LB, Kucheryavaya AY, et al; International Society of Heart and Lung Transplantation. The registry of the international society for heart and lung transplantation: 29th official adult heart transplant report - 2012. J Heart Lung Transplant. 2012;31(10):1052-1064.

16. Christie JD, Edwards LB, Kucheryavaya AY, et al; International Society of Heart and Lung Transplantation. The registry of the international society for heart and lung transplantation: 29th adult lung and heart-lung transplant report - 2012. J Heart Lung Transplant. 2012;31(10):1073-1086.

17. Marcén R. Immunosuppressive drugs in kidney transplantation: impact on patient survival, and incidence of cardiovascular disease, malignancy and infection. Drugs. 2009;69(16):2227-2243.

18. Shrestha BM, Haylor JL. Factors influencing long-term outcomes following renal transplantation: a review. JNMA J Nepal Med Assoc. 2007;46(167):136-142.

19. Hingorani S. Chronic kidney disease after liver, cardiac, lung, heart-lung, and hematopoietic stem cell transplant. Pediatr Nephrol. 2008;23(6):879-888.

20. Goetzmann L, Irani S, Schwegler K, et al. Lung function, sociodemographic characteristics, and psychological reaction to transplant associated with chronic stress among lung recipients. Anxiety Stress Coping. 2010;23(2):213-233. 
21. De Baere C, Delva D, Kloeck A, et al. Return to work and social participation: does type of organ transplantation matter? Transplantation. 2010;89(8):1009-1015.

22. Paris W, White-Williams C. Social adaptation after cardiothoracic transplantation: a review of the literature. J Cardiovasc Nurs. 2005; 20(5 Suppl):S67-S73.

23. Grady KL, Wang E, White-Williams C, et al. Factors associated with stress and coping at 5 and 10 years after heart transplantation. J Heart Lung Transplant. 2013;32(4):437-446.

24. Goetzmann L, Lieberherr M, Krombholz L, et al. Subjektives Erleben nach einer Organtransplantation - eine qualitative Studie mit $120 \mathrm{Herz}$-, Lungen-, Leber- und Nierenempfängern. [Subjective experiences following organ transplantation - a qualitative study of 120 heart, lung, liver, and kidney recipients]. Z Psychosom Med Psychother. 2010; 56(3):268-282. German.

25. Butt Z, Parikh ND, Skaro AI, Ladner D, Cella D. Quality of life, risk assessment, and safety research in liver transplantation: new frontiers in health services and outcomes research. Curr Opin Organ Transplant 2012;17(3):241-247.

26. Goetzmann L, Ruegg L, Stamm M, et al. Psychosocial profiles after transplantation: a 24-month follow-up of heart, lung, liver, kidney and allogeneic bone-marrow patients. Transplantation. 2008; 86(5):662-668.

27. Palmer S, Vecchio M, Craig JC, et al. Prevalence of depression in chronic kidney disease: systematic review and meta-analysis of observational studies. Kidney Int. 2013;84(1):179-191.

28. Zalai D, Szeifert L, Novak M. Psychological distress and depression in patients with chronic kidney disease. Semin Dial. 2012;25(4): $428-438$

29. Chilcot J, Spencer BW, Maple H, Mamode N. Depression and kidney transplantation. Transplantation. 2014;97(7):717-721.

30. Dobbels F, Verleden G, Dupont L, Vanhaecke J, De Geest S. To transplant or not? The importance of psychosocial and behavioural factors before lung transplantation. Chron Respir Dis. 2006;3(1):39-47.

31. Dew MA, DiMartini AF, DeVito Dabbs AJ, et al. Onset and risk factors for anxiety and depression during the first 2 years after lung transplantation. Gen Hosp Psychiatry. 2012;34(2):127-138.

32. Corruble E, Barry C, Varescon I, Falissard B, Castaing D, Samuel D. Depressive symptoms predict long-term mortality after liver transplantation. J Psychosom Res. 2011;71(1):32-37.

33. Mullish BH, Kabir MS, Thursz MR, Dhar A. Depression and the use of antidepressants in patients with chronic liver disease or liver transplantation. Aliment Pharmacol Ther. 2014;40(8):880-892.

34. Errichiello L, Picozzi D, de Notaris EB. Prevalence of psychiatric disorders and suicidal ideation in liver transplanted patients: a cross-sectional study. Clin Res Hepatol Gastroenterol. 2014;38(1): 55-62.

35. Rogal SS, Dew MA, Fontes P, DiMartini AF. Early treatment of depressive symptoms and long-term survival after liver transplantation. Am J Transplant. 2013;13(4):928-935.

36. Rogal SS, Landsittel D, Surman O, Chung RT, Rutherford A. Pretransplant depression, antidepressant use, and outcomes of orthotopic liver transplantation. Liver Transpl. 2011;17(3):251-260.

37. Dobbels F, De Geest S, Martin S, Van Cleemput J, Droogne W, Vanhaecke J. Prevalence and correlates of depression symptoms at 10 years after heart transplantation: continuous attention required. Transpl Int. 2004;17(8):424-431.

38. Fusar-Poli P, Martinelli V, Klersy C, et al. Depression and quality of life in patients living 10 to 18 years beyond heart transplantation. J Heart Lung Transplant. 2005;24(12):2269-2278.

39. Yohannes AM, Willgoss TG, Baldwin RC, Connolly MJ. Depression and anxiety in chronic heart failure and chronic obstructive pulmonary disease: prevalence, relevance, clinical implications and management principles. Int J Geriatr Psychiatry. 2010;25(12):1209-1221.

40. Dew MA, DiMartini AF. Psychological disorders and distress after adult cardiothoracic transplantation. J Cardiovasc Nurs. 2005; 20(5 Suppl):S51-S66.
41. Corbett C, Armstrong MJ, Parker R, Webb K, Neuberger JM. Mental health disorders and solid-organ transplant recipients. Transplantation. 2013;96(7):593-600.

42. Annema C, Roodbol PF, Stewart RE, Porte RJ, Ranchor AV. Prevalence of psychological problems and associated transplant-related variables at different time periods after liver transplantation. Liver Transpl. 2015;21(4):524-538.

43. Goetzmann L, Klaghofer R, Wagner-Huber R, et al. Psychosocial vulnerability predicts psychosocial outcome after an organ transplant: results of a prospective study with lung, liver, and bone-marrow patients. J Psychosom Res. 2007;62(1):93-100.

44. Archonti C, D’Amelio R, Klein T, Schäfers HJ, Sybrecht GW, Wilkens H. Gesundheitsbezogene Lebensqualität und soziale Unterstützung bei Patienten auf der Warteliste und nach einer Lungentransplantation. [Physical quality of life and social support in patients on the waiting list and after a lung transplantation]. Psychother Psychosom Med Psychol. 2004;54(1):17-22. German.

45. Milaniak I, Wilczek-Rużyczka E, Przybyłowski P, Wierzbicki K, Siwińska J, Sadowski J. Psychological predictors (personal recourses) of quality of life for heart transplant recipients. Transplant Proc. 2014;46(8):2839-2843.

46. Weng LC, Dai YT, Huang HL, Chiang YJ. Self-efficacy, self-care behaviours and quality of life of kidney transplant recipients. $J A d v$ Nurs. 2010;66(4):828-838.

47. White-Williams C, Grady KL, Myers S, et al. The relationships among satisfaction with social support, quality of life, and survival 5 to 10 years after heart transplantation. J Cardiovasc Nurs. 2013;28(5):407-416.

48. Dew MA, Switzer GE, DiMartini AF, Matukaitis J, Fitzgerald MG, Kormos RL. Psychosocial assessments and outcomes in organ transplantation. Prog Transplant. 2000;10(4):239-259; quiz 260-261.

49. Psychosocial Outcomes Workgroup of the Nursing and Social Sciences Council of the International Society for Heart and Lung Transplantation; Cupples S, Dew MA, et al. Report of the Psychosocial Outcomes Workgroup of the Nursing and Social Sciences Council of the International Society for Heart and Lung Transplantation: present status of research on psychosocial outcomes in cardiothoracic transplantation: review and recommendations for the field. J Heart Lung Transplant. 2006;25(6):716-725.

50. Rosenberger EM, Dew MA, Crone C, DiMartini AF. Psychiatric disorders as risk factors for adverse medical outcomes after solid organ transplantation. Curr Opin Organ Transplant. 2012;17(2):188-192.

51. Griva K, Davenport A, Newman SP. Health-related quality of life and long-term survival and graft failure in kidney transplantation: a 12-year follow-up study. Transplantation. 2013;95(5):740-749.

52. DiMartini A, Dew MA, Chaiffetz D, Fitzgerald MG, Devera ME, Fontes P. Early trajectories of depressive symptoms after liver transplantation for alcoholic liver disease predicts long-term survival. Am J Transplant. 2011;11(6):1287-1295.

53. Goetzmann L, Klaghofer R, Wagner-Huber R, et al. Psychosozialer Beratungsbedarf vor und nach einer Lungen-, Leber- oder allogenen Knochenmarkstransplantation - Ergebnisse einer prospektiven Studie. [Psychosocial need for counselling before and after a lung, liver or allogenic bone marrow transplant - results of a prospective study]. $Z$ Psychosom Med Psychother. 2006;52(3):230-242. German.

54. Schulz KH, Ewers H, Rogiers X, Koch U. Bedarf und Inanspruchnahme psychosozialer Betreuung nach Lebertransplantation. [Need and utilization of psychosocial care after liver transplantation]. Psychother Psychosom Med Psychol. 2007;57(5):221-230. German.

55. Engle D. Psychosocial aspects of the organ transplant experience: what has been established and what we need for the future. J Clin Psychol. 2001;57(4):521-549.

56. Heilmann C, Kuijpers N, Beyersdorf F, et al. Supportive psychotherapy for patients with heart transplantation or ventricular assist devices. Eur J Cardiothorac Surg. 2011;39(4):e44-e50.

57. Köllner V, Archonti C. Psychotherapeutische Interventionen vor und nach Organtransplantation. [Psychotherapeutic interventions before and after organ transplantation]. Verhaltenstherapie. 2003;13(1):47-60. German 
58. Tigges-Limmer K, Leppert K, Strauss B, Wahlers T. Hypnotherapie in der Herztransplantation. [Hypnotherapy in heart transplantation]. Psychotherapeut. 2005;50(1):52-56. German.

59. Rodrigue JR, Mandelbrot DA, Pavlakis M. A psychological intervention to improve quality of life and reduce psychological distress in adults awaiting kidney transplantation. Nephrol Dial Transplant. 2011;26(2):709-715.

60. Gross CR, Kreitzer MJ, Thomas W, et al. Mindfulness-based stress reduction for solid organ transplant recipients: a randomized controlled trial. Altern Ther Health Med. 2010;16(5):30-38.

61. Rodrigue JR, Dimitri N, Reed A, Antonellis T, Hanto DW, Curry M. Quality of life and psychosocial functioning of spouse/partner caregivers before and after liver transplantation. Clin Transplant. 2011;25(2): 239-247.

62. Corruble E, Barry C, Varescon I, et al. Report of depressive symptoms on waiting list and mortality after liver and kidney transplantation: a prospective cohort study. BMC Psychiatry. 2011;11:182. doi: 10.1186/1471-244X-11-182.

63. Teperman LW. Impact of pretransplant hepatic encephalopathy on liver posttransplantation outcomes. Int J Hepatol. 2013;2013:952828. doi: $10.1155 / 2013 / 952828$.

64. Da Matta SM, Moreira JM, Kummer AM, Barbosa IG, Teixeira AL, Silva AC. Cognitive alterations in chronic kidney disease: an update. J Bras Nefrol. 2014;36(2):241-245.

65. Hajduk AM, Kiefe CI, Person SD, Gore JG, Saczynski JS. Cognitive change in heart failure: a systematic review. Circ Cardiovasc Qual Outcomes. 2013;6(4):451-460.

66. Hoffman BM, Blumenthal JA, Carney RC, et al. Changes in neurocognitive functioning following lung transplantation. Am J Transplant. 2012; 12(9):2519-2525.

67. Potts SG. Transplant psychiatry. J R Coll Physicians Edinb. 2009; 39(4):331-336.

68. Jowsey SG, Taylor ML, Schneekloth TD, Clark MM. Psychosocial challenges in transplantation. $J$ Psychiatr Pract. 2001;7(6):404-414.

69. Clemens KK, Thiessen-Philbrook H, Parikh CR, et al; Donor Nephrectomy Outcomes Research (DONOR) Network. Psychosocial health of living kidney donors: a systematic review. Am J Transplant. 2006;6(12):2965-2977.

70. Morgan BR, Ibrahim HN. Long-term outcomes of kidney donors. Curr Opin Nephrol Hypertens. 2011;20(6):605-609.

71. Parikh ND, Ladner D, Abecassis M, Butt Z. Quality of life for donors after living donor liver transplantation: a review of the literature. Liver Transpl. 2010;16(12):1352-1358.

72. Xu DW, Long XD, Xia Q. A review of life quality in living donors after liver transplantation. Int J Clin Exp Med. 2015;8(1):20-26.

73. Delanaye P, Weekers L, Dubois BE, et al. Outcome of the living kidney donor. Nephrol Dial Transplant. 2012;27(1):41-50.

74. Dor FJ, Massey EK, Frunza M, et al. New classification of ELPAT for living organ donation. Transplantation. 2011;91(9):935-938.

75. Duerinckx N, Timmerman L, Van Gogh J, et al; ELPAT Psychological Care for Living Donors and Recipients Working Group. Predonation psychosocial evaluation of living kidney and liver donor candidates: a systematic literature review. Transpl Int. 2014;27(1): $2-18$.

76. Berlakovich GA. Challenges in transplantation for alcoholic liver disease. World J Gastroenterol. 2014;20(25):8033-8039.

77. Varma V, Webb K, Mirza DF. Liver transplantation for alcoholic liver disease. World J Gastroenterol. 2010;16(35):4377-4393.

78. Lucey MR. Liver transplantation in patients with alcoholic liver disease. Liver Transpl. 2011;17(7):751-759.

79. Iruzubieta P, Crespo J, Fábrega E. Long-term survival after liver transplantation for alcoholic liver disease. World J Gastroenterol. 2013; 19(48):9198-9208.

80. Burra P, Senzolo M, Adam R, et al; ELITA; ELTR Liver Transplant Centers. Liver transplantation for alcoholic liver disease in Europe: a study from the ELTR (European Liver Transplant Registry). Am J Transplant. 2010;10(1):138-148.
81. O'Shea RS, Dasarathy S, McCullough AJ. Alcoholic liver disease. Am J Gastroenterol. 2010;105(1):14-32; quiz 33.

82. Neuberger J, Schulz KH, Day C, et al. Transplantation for alcoholic liver disease. J Hepatol. 2002;36(1):130-137.

83. Teli MR, Day CP, Burt AD, Bennett MK, James OF. Determinants of progression to cirrhosis or fibrosis in pure alcoholic fatty liver. Lancet. 1995;346(8981):987-990.

84. Rowley AA, Hong BA, Chapman W, Crippin JS. The psychiatric diagnosis of alcohol abuse and the medical diagnosis of alcoholic related liver disease: effects on liver transplant survival. J Clin Psychol Med Settings. 2010;17(3):195-202.

85. Faure S, Herrero A, Jung B, et al. Excessive alcohol consumption after liver transplantation impacts on long-term survival, whatever the primary indication. J Hepatol. 2012;57(2):306-312.

86. Leithead JA, Ferguson JW, Hayes PC. Smoking-related morbidity and mortality following liver transplantation. Liver Transpl. 2008; 14(8):1159-1164.

87. Cuadrado A, Fábrega E, Casafont F, Pons-Romero F. Alcohol recidivism impairs long-term patient survival after orthotopic liver transplantation for alcoholic liver disease. Liver Transpl. 2005; 11(4):420-426.

88. Rice JP, Lucey MR. Should length of sobriety be a major determinant in liver transplant selection? Curr Opin Organ Transplant. 2013; 18(3):259-264.

89. Pfitzmann R, Schwenzer J, Rayes N, Seehofer D, Neuhaus R, Nüssler NC. Long-term survival and predictors of relapse after orthotopic liver transplantation for alcoholic liver disease. Liver Transpl. 2007; 13(2):197-205.

90. De Gottardi A, Spahr L, Gelez P, et al. A simple score for predicting alcohol relapse after liver transplantation: results from 387 patients over 15 years. Arch Intern Med. 2007;167(11):1183-1188.

91. DiMartini A, Day N, Dew MA, et al. Alcohol consumption patterns and predictors of use following liver transplantation for alcoholic liver disease. Liver Transpl. 2006;12(5):813-820.

92. Gedaly R, McHugh PP, Johnston TD, et al. Predictors of relapse to alcohol and illicit drugs after liver transplantation for alcoholic liver disease. Transplantation. 2008;86(8):1090-1095.

93. Mathurin P, Moreno C, Samuel D, et al. Early liver transplantation for severe alcoholic hepatitis. $N$ Engl J Med. 2011;365(19): $1790-1800$

94. Donckier V, Lucidi V, Gustot T, Moreno C. Ethical considerations regarding early liver transplantation in patients with severe alcoholic hepatitis not responding to medical therapy. J Hepatol. 2014; 60(4):866-871.

95. Gramenzi A, Gitto S, Caputo F, et al. Liver transplantation for patients with alcoholic liver disease: an open question. Dig Liver Dis. 2011; 43(11):843-849.

96. McCallum S, Masterton G. Liver transplantation for alcoholic liver disease: a systematic review of psychosocial selection criteria. Alcohol Alcohol. 2006;41(4):358-363.

97. Dom G, Francque S, Michielsen P. Risk for relapse of alcohol use after liver transplantation for alcoholic liver disease: a review and proposal of a set of risk assessment criteria. Acta Gastroenterol Belg. 2010;73(2):247-251.

98. Rustad JK, Stern TA, Prabhakar M, Musselman D. Risk factors for alcohol relapse following orthotopic liver transplantation: a systematic review. Psychosomatics. 2015;56(1):21-35.

99. Hartl J, Scherer MN, Loss M, et al. Strong predictors for alcohol recidivism after liver transplantation: non-acceptance of the alcohol problem and abstinence of $<3$ months. Scand J Gastroenterol. 2011;46(10):1257-1266.

100. Erim Y, Möller E, Beckebaum S, Gerken G, Broelsch CE, Senf WE. Ein manualisiertes Gruppentherapiekonzept für alkoholabhängige Patienten vor der Lebertransplantation. [Manualised group therapy concept for patients with alcoholic cirrhosis awaiting liver transplantation]. Z Psychosom Med Psychother. 2006;52(3):243-258. German 
101. Kiefer F, Mann K. Evidenzbasierte Behandlung der Alkoholabhängigkeit. [Evidence-based treatment of alcoholism]. Nervenarzt. 2007;78(11):1321-1329; quiz 1330-1331. German.

102. Ortega F, Díaz-Corte C, Valdés C. Adherence to immunosuppressor medication in renal transplanted patients. World J Clin Urol. 2015; 4(1):27-37.

103. De Bleser L, Matteson M, Dobbels F, Russell C, De Geest S. Interventions to improve medication-adherence after transplantation: a systematic review. Transpl Int. 2009;22(8):780-797.

104. Corbett C, Armstrong MJ, Neuberger J. Tobacco smoking and solid organ transplantation. Transplantation. 2012;94(10):979-987.

105. Dew MA, DiMartini AF, De Vito Dabbs A, et al. Rates and risk factors for nonadherence to the medical regimen after adult solid organ transplantation. Transplantation. 2007;83(7):858-873.

106. Dobbels F, Hames A, Aujoulat I, Heaton N, Samyn M. Should we retransplant a patient who is non-adherent? A literature review and critical reflection. Pediatr Transplant. 2012;16(1):4-11.

107. Dew MA, DiMartini AF, Steel J, et al. Meta-analysis of risk for relapse to substance use after transplantation of the liver or other solid organs. Liver Transpl. 2008;14(2):159-172.

108. De Bleser L, Dobbels F, Berben L, et al. The spectrum of nonadherence with medication in heart, liver, and lung transplant patients assessed in various ways. Transpl Int. 2011;24(9):882-891.

109. Dobbels F, Berben L, De Geest S, et al; Transplant360 Task Force. The psychometric properties and practicability of self-report instruments to identify medication nonadherence in adult transplant patients: a systematic review. Transplantation. 2010;90(2):205-219.

110. De Geest S, Vanhaecke J. Methodological issues in transplant compliance research. Transplant Proc. 1999;31(4A):81S-83S.

111. Prendergast MB, Gaston RS. Optimizing medication adherence: an ongoing opportunity to improve outcomes after kidney transplantation. Clin J Am Soc Nephrol. 2010;5(7):1305-1311.

112. Schäfer-Keller P, Steiger J, Bock A, Denhaerynck K, De Geest S. Diagnostic accuracy of measurement methods to assess non-adherence to immunosuppressive drugs in kidney transplant recipients. $\mathrm{Am} \mathrm{J}$ Transplant. 2008;8(3):616-626.

113. Butler JA, Peveler RC, Roderick P, Horne R, Mason JC. Measuring compliance with drug regimens after renal transplantation: comparison of selfreport and clinician rating with electronic monitoring. Transplantation. 2004;77(5):786-789.

114. Hsiau M, Fernandez HE, Gjertson D, Ettenger RB, Tsai EW. Monitoring nonadherence and acute rejection with variation in blood immunosuppressant levels in pediatric renal transplantation. Transplantation. 2011;92(8):918-922.

115. Maclean JR, Pfister M, Zhou Z, Roy A, Tuomari VA, Heifets M. Quantifying the impact of nonadherence patterns on exposure to oral immunosuppressants. Ther Clin Risk Manag. 2011;7:149-156.

116. Dobbels F, Vanhaecke J, Dupont L, et al. Pretransplant predictors of posttransplant adherence and clinical outcome: an evidence base for pretransplant psychosocial screening. Transplantation. 2009; 87(10):1497-1504.

117. Kugler C, Geyer S, Gottlieb J, Simon A, Haverich A, Dracup K. Symptom experience after solid organ transplantation. J Psychosom Res. 2009;66(2):101-110.

118. Burra P, Germani G, Gnoato F, et al. Adherence in liver transplant recipients. Liver Transpl. 2011;17(7):760-770.

119. Bunzel B, Laederach-Hofmann K. Solid organ transplantation: are there predictors for posttransplant noncompliance? A literature overview. Transplantation. 2000;70(5):711-716.

120. Rosenberger EM, Dew MA, DiMartini AF, DeVito Dabbs AJ, Yusen RD. Psychosocial issues facing lung transplant candidates, recipients and family caregivers. Thorac Surg Clin. 2012;22(4):517-529.

121. Dew MA, Roth LH, Thompson ME, Kormos RL, Griffith BP. Medical compliance and its predictors in the first year after heart transplantation. J Heart Lung Transplant. 1996;15(6):631-645.

122. Prihodova L, Nagyova I, Rosenberger J, et al. Health-related quality of life 3 months after kidney transplantation as a predictor of survival over 10 years: a longitudinal study. Transplantation. 2014;97(11): 1139-1145.
123. Dew MA, Switzer GE, Goycoolea JM, et al. Does transplantation produce quality of life benefits? A quantitative analysis of the literature. Transplantation. 1997;64(9):1261-1273.

124. Bravata DM, Olkin I, Barnato AE, Keeffe EB, Owens DK. Healthrelated quality of life after liver transplantation: a meta-analysis. Liver Transpl Surg. 1999;5(4):318-331.

125. Cameron JI, Whiteside C, Katz J, Devins GM. Differences in quality of life across renal replacement therapies: a meta-analytic comparison. Am J Kidney Dis. 2000;35(4):629-637.

126. Joseph JT, Baines LS, Morris MC, Jindal RM. Quality of life after kidney and pancreas transplantation: a review. Am J Kidney Dis. 2003;42(3):431-445.

127. Taylor R, Franck LS, Gibson F, Dhawan A. A critical review of the health-related quality of life of children and adolescents after liver transplantation. Liver Transpl. 2005;11(1):51-60. discussion 7-9.

128. Liem YS, Bosch JL, Arends LR, Heijenbrok-Kal MH, Hunink MG. Quality of life assessed with the medical outcomes study short form 36-item health survey of patients on renal replacement therapy: a systematic review and meta-analysis. Value Health. 2007;10(5): 390-397.

129. Tome S, Wells JT, Said A, Lucey MR. Quality of life after liver transplantation. A systematic review. J Hepatol. 2008;48(4): 567-577.

130. Landreneau K, Lee K, Landreneau MD. Quality of life in patients undergoing hemodialysis and renal transplantation - a meta-analytic review. Nephrol Nurs J. 2010;37(1):37-44.

131. Tonelli M, Wiebe N, Knoll G, et al. Systematic review: kidney transplantation compared with dialysis in clinically relevant outcomes. Am J Transplant. 2011;11(10):2093-2109.

132. Yang LS, Shan LL, Saxena A, Morris DL. Liver transplantation: a systematic review of long-term quality of life. Liver Int. 2014;34(9): 1298-1313.

133. Rosenberger EM, Fox KR, DiMartini AF, Dew MA. Psychosocial factors and quality-of-life after heart transplantation and mechanical circulatory support. Curr Opin Organ Transplant. 2012;17(5): 558-563.

134. Choong CK, Meyers BF. Quality of life after lung transplantation. Thorac Surg Clin. 2004;14(3):385-407.

135. Singer LG. Cost-effectiveness and quality of life: benefits of lung transplantation. Respir Care Clin N Am. 2004;10(4):449-457.

136. Grady KL. Quality of life after heart transplantation: are things really better? Curr Opin Cardiol. 2003;18(2):129-135.

137. Sudan D. Long-term outcomes and quality of life after intestine transplantation. Curr Opin Organ Transplant. 2010;15(3):357-360.

138. Anthony SJ, Pollock Barziv S, Ng VL. Quality of life after pediatric solid organ transplantation. Pediatr Clin North Am. 2010;57(2):559-574.

139. Kniepeiss D, Wagner D, Pienaar S, et al. Solid organ transplantation: technical progress meets human dignity: a review of the literature considering elderly patients' health related quality of life following transplantation. Ageing Res Rev. 2012;11(1):181-187.

140. Burra P, De Bona M. Quality of life following organ transplantation. Transpl Int. 2007;20(5):397-409.

141. Ortega F, Valdés C, Ortega T. Quality of life after solid organ transplantation. Transplant Rev (Orlando). 2007;21(3):155-170.

142. Feurer ID, Speroff T, Harrison C, Wright Pinson C. Healthrelated quality of life before and after solid organ transplantation. Measurement consideration, reported outcomes, and future directions. Minerva Chir. 2002;57(3):257-271.

143. Schulz KH, Kraft S, Ewers H, Wein C, Kroencke S, Koch U. Lebensqualität nach Organtransplantation. [Quality of life after organ transplantation]. Bundesgesundheitsblatt Gesundheitsforschung Gesundheitsschutz. 2002;45(10):782-794. German.

144. Molzahn AE. Quality of life after organ transplantation. J Adv Nurs. 1991;16(9):1042-1047.

145. Butt Z, Yount SE, Caicedo JC, Abecassis MM, Cella D. Quality of life assessment in renal transplant: review and future directions. Clin Transplant. 2008;22(3):292-303. 
146. Jay CL, Butt Z, Ladner DP, Skaro AI, Abecassis MM. A review of quality of life instruments used in liver transplantation. J Hepatol. 2009;51(5):949-959.

147. Ware JE Jr, Sherbourne CD. The MOS 36-item short-form health survey (SF-36). I. Conceptual framework and item selection. Med Care. 1992; 30(6):473-483.

148. Burra P, Germani G, Masier A, et al. Sexual dysfunction in chronic liver disease: is liver transplantation an effective cure? Transplantation. 2010;89(12):1425-1429.

149. Muehrer RJ. Sexuality, an important component of the quality of life of the kidney transplant recipient. Transplant Rev (Orlando). 2009; 23(4):214-223.

150. Duffy JP, Kao K, Ko CY, et al. Long-term patient outcome and quality of life after liver transplantation: analysis of 20-year survivors. Ann Surg. 2010;252(4):652-661.

151. Neipp M, Karavul B, Jackobs S, et al. Quality of life in adult transplant recipients more than 15 years afterkidney transplantation. Transplantation. 2006;81(12):1640-1644.

152. Rutherford RM, Fisher AJ, Hilton C, et al. Functional status and quality of life in patients surviving 10 years after lung transplantation. Am J Transplant. 2005;5(5):1099-1104.

153. Karam VH, Gasquet I, Delvart V, et al. Quality of life in adult survivors beyond 10 years after liver, kidney, and heart transplantation. Transplantation. 2003;76(12):1699-1704.

154. Bownik H, Saab S. Health-related quality of life after liver transplantation for adult recipients. Liver Transpl. 2009;15(Suppl 2):S42-S49.

155. Pinson CW, Feurer ID, Payne JL, Wise PE, Shockley S, Speroff T. Health-related quality of life after different types of solid organ transplantation. Ann Surg. 2000t;232(4):597-607.

156. Nickel R, Wunsch A, Egle UT, Lohse AW, Otto G. The relevance of anxiety, depression, and coping in patients after liver transplantation. Liver Transpl. 2002;8(1):63-71.

157. Hathaway DK, Winsett RP, Johnson C, et al. Post kidney transplant quality of life prediction models. Clin Transplant. 1998;12(3):168-174.

158. Whiting JF, Nabel J, Grossman P, Martin JE, Hanto DW, First MR. Clinical determinants of health-related quality of life in recipients of solid organ transplants. J Surg Outcomes. 1999;2(1):21-26.

159. Kugler C, Gottlieb J, Warnecke G, et al. Health-related quality of life after solid organ transplantation: a prospective, multiorgan cohort study. Transplantation. 2013;96(3):316-323.

160. Goetzmann L, Sarac N, Ambühl P, et al. Psychological response and quality of life after transplantation: a comparison between heart, lung, liver and kidney recipients. Swiss Med Wkly. 2008;138(33-34):477-483.

161. Littlefield C, Abbey S, Fiducia D, et al. Quality of life following transplantation of the heart, liver, and lungs. Gen Hosp Psychiatry. 1996;18(6 Suppl):36S-47S.

162. Rosenberger J, van Dijk JP, Nagyova I, et al. Predictors of perceived health status in patients after kidney transplantation. Transplantation. 2006;81(9):1306-1310.

163. Van der Mei SF, Krol B, van Son WJ, de Jong PE, Groothoff JW, van den Heuvel WJ. Social participation and employment status after kidney transplantation: a systematic review. Qual Life Res. 2006;15(6): 979-994.
164. Bravata DM, Olkin I, Barnato AE, Keeffe EB, Owens DK. Employment and alcohol use after liver transplantation for alcoholic and nonalcoholic liver disease: a systematic review. Liver Transpl. 2001;7(3): 191-203.

165. Huda A, Newcomer R, Harrington C, Keeffe EB, Esquivel CO. Employment after liver transplantation: a review. Transplant Proc. 2015;47(2):233-239.

166. Slakey DP, Rosner M. Disability following kidney transplantation: the link to medication coverage. Clin Transplant. 2007;21(2):224-228.

167. Kristen AV, Ammon K, Koch A, et al. Return to work after heart transplantation: discrepancy with subjective work ability. Transplantation. 2009;87(7):1001-1005.

168. Matas AJ, Lawson W, McHugh L, et al. Employment patterns after successful kidney transplantation. Transplantation. 1996;61(5): 729-733.

169. White-Williams C, Jalowiec A, Grady K. Who returns to work after heart transplantation? J Heart Lung Transplant. 2005;24(12):2255-2261.

170. McGee J, Jackson NR, Slakey DP. Disability and kidney transplantation in the United States. Clin Transplant. 2012;26(3):377-381.

171. Monroe J, Raiz L. Barriers to employment following renal transplantation: implications for the social work professional. Soc Work Health Care. 2005;40(4):61-81.

172. Van der Mei SF, Kuiper D, Groothoff JW, van den Heuvel WJ, van Son WJ, Brouwer S. Long-term health and work outcomes of renal transplantation and patterns of work status during the end-stage renal disease trajectory. J Occup Rehabil. 2011;21(3):325-334.

173. Chisholm-Burns MA, Erickson SR, Spivey CA, Kaplan B. Health-related quality of life and employment among renal transplant recipients. Clin Transplant. 2012;26(3):411-417.

174. White-Williams C, Wang E, Rybarczyk B, Grady KL. Factors associated with work status at 5 and 10 years after heart transplantation. Clin Transplant. 2011;25(6):E599-E605.

175. Rainer JP, Thompson CH, Lambros H. Psychological and psychosocial aspects of the solid organ transplant experience - a practice review. Psychotherapy (Chic). 2010;47(3):403-412.

176. Dew MA, Manzetti J, Goycoolea JR, et al. (2002). Psychosocial Aspects of Transplantation. Medscape; 2002. Available from: http:// www.medscape.com/viewarticle/436541_print. Accessed January 26, 2015.

177. Thys K, Schwering KL, Siebelink M, et al; ELPAT Pediatric Organ Donation and Transplantation Working Group. Psychosocial impact of pediatric living-donor kidney and liver transplantation on recipients, donors, and the family: a systematic review. Transpl Int. 2015; 28(3):270-280.

178. Taylor RM, Franck LS, Dhawan A, Gibson F. The stories of young people living with a liver transplant. Qual Health Res. 2010;20(8): 1076-1090.

179. Tong A, Morton R, Howard K, Craig JC. Adolescent experiences following organ transplantation: a systematic review of qualitative studies. J Pediatr. 2009;155(4):542-549.

180. Bell LE, Bartosh SM, Davis CL, et al. Adolescent transition to adult care in solid organ transplantation: a consensus conference report. Am J Transplant. 2008;8(11):2230-2242.
Transplant Research and Risk Management

\section{Publish your work in this journal}

Transplant Research and Risk Management is an international, peerreviewed open access journal focusing on all aspects of transplantation and risk management to achieve optimal outcomes in the recipient improving survival and quality of life. The journal welcomes submitted papers covering original research, basic science, clinical studies,

\section{Dovepress}

reviews \& evaluations, guidelines, expert opinion and commentary, case reports and extended reports. The manuscript management system is completely online and includes a very quick and fair peer-review system, which is all easy to use. Visit http://www.dovepress.com/ testimonials.php to read real quotes from published authors. 